\title{
Características reprodutivas de ovelhas Morada Nova e Somalis Brasileira
}

Rafael Teixeira de Sousa ${ }^{1 *}$, Juliete de Lima Gonçalves², Natália Lívia de Oliveira Fonteles ${ }^{2}$, Claudiane Morais dos Santos ${ }^{3}$, Gisele Dela Ricci ${ }^{1}$, Fernando Henrique Melo Andrade Rodrigues de Albuquerque ${ }^{4}$, Francisco Eden Paiva Fernandes ${ }^{4}$, Marco Aurélio Delmondes Bomfim ${ }^{4}$.

${ }^{1}$ Programa de Pós-graduação em Nutrição e Produção Animal, Faculdade de Medicina Veterinária e Zootecnia, Universidade de São Paulo, Pirassununga, São Paulo.

${ }^{2}$ Programa de Pós Graduação em Zootecnia, Universidade Federal da Paraíba, Areia, Paraíba.

${ }^{3}$ Zootecnista autônoma.

${ }^{4}$ Pesquisador da Embrapa Caprinos e Ovinos, Sobral, Ceará.

*Autor para correspondência: rafaelvnp@usp.br

RESUMO. A Morada Nova e a Somalis Brasileira constituem uma das principais raças de ovinos deslanados do Nordeste do Brasil. São exploradas para carne e pele, e apresentam características reprodutivas peculiares que garantem um bom desempenho dessas raças mesmo sob condições menos favoráveis de criação. Ambas as raças, apresentam um elevado potencial reprodutivo, onde as fêmeas destes grupos genéticos são poliéstricas anuais, apresentando estro, ovulação e parição durante todo o ano. Entretanto, a eficiência reprodutiva desses animais, por várias razões precisa ser melhorada no Nordeste brasileiro. O status nutricional dessas ovelhas é relevante, quando se deseja alcançar melhorias na sua capacidade reprodutiva e produtiva, e assegurar um plano nutricional adequado é fundamental para o aumento dos índices zootécnicos

Palavras chave: Índices zootécnicos, ovinos, produção, reprodução.

\section{Reproductive Characteristics of Morada Nova and Brazilian Somalis sheep breeds}

\begin{abstract}
Morada Nova and Brazilian Somalis are majorhair sheep breeds of Northeast Brazil. They are exploited for meat and skin, and have characteristics peculiar reproductive ensuring good performance of these breeds even under less favorable conditions for the creation. Both breeds have a high reproductive potential, where females of these groups are annual genetic poliestricas, presenting estrus, ovulation and calving during the whole year. However, reproductive efficiency is important factors in sheep production systems and for various reasons need to be improved in the Brazilian Northeast. The nutritional status is a major factor, when it wants to achieve improvements in the productive and reproductive capacity of the herd, to ensure an appropriate nutritional plan is essential for the increase of zootechnicals parameters.
\end{abstract}

Key words: zootechnical indexes, sheep, production, reproduction.

\section{Introdução}

A ovinocultura é uma atividade econômica explorada em todos os continentes, estando presente em áreas sob as mais diversas características climáticas, edáficas e botânicas. A expansão desta atividade tem apresentado grande importância nos sistemas agropecuários, especialmente na agricultura familiar, onde tem possibilitado a geração de produtos comercializáveis como a carne e a pele (Viana, 2008).

A região Nordeste do Brasil é detentora do maior efetivo de ovinos do país, com destaque para a produção de carne. Entretanto, o crescimento deste setor ainda necessita de pesquisas voltadas para a exploração dos diferentes potenciais para a produção de carne das raças ovinas naturalizadas, criadas nos mais diversos sistemas de produção, bem como 
investimentos em qualificação da mão de obra, buscando sempre à consolidação da atividade (Sousa, 2012).

Dentre os ovinos deslanados naturalizados com aptidão para corte, destacam - se as raças Morada Nova e Somalis Brasileira (Magalhães et al., 2010, Silva et al., 1998). Esses animais possuem características morfofisiológicas peculiares às condições climáticas do Nordeste brasileiro, o que as tornam adaptáveis e resistentes às adversidades (Sousa, 2012). As fêmeas destes grupos genéticos são poliéstricas anuais, podendo entrar em estro, ovulação e parição durante todo o ano. No entanto, a eficiência reprodutiva, que é um índice importante na produtividade do rebanho está na dependência de vários outros fatores, como estratégias de manejo nutricional e sanitário que garantam a expressão desse potencial (Bomfim et al., 2014). O objetivo desta revisão é discutir os principais aspectos reprodutivos das raças Morada Nova e Somalis Brasileira e evidenciar as potencialidades desses animais dentro dos sistemas de produção da ovinocultura.

\section{Aspectos reprodutivos da fêmea ovina}

As fêmeas ovinas nascem com um potencial genético para uma atividade reprodutiva cíclica, cuja expressão, é dependente da maturidade hipotalâmica e dos centros sexuais cerebrais (Chemineau \& Delgadillo, 1993). O início da atividade sexual na fêmea ovina é determinado pelo aparecimento da puberdade, caracterizada pela primeira ovulação. A idade a puberdade nesses animais é influenciada tanto por fatores de ordem ambiental quanto genotípica, tais como: raça, plano nutricional, clima, interação social, época de nascimento e desenvolvimento ponderal (Jainudeen et al., 2004).

O ciclo estral na ovelha pode ser dividido em duas fases: a primeira fase é denominada de folicular que tem duração média de quatro dias e é marcada pelo desenvolvimento do folículo ovariano culminando ou não na ovulação. A segunda fase é conhecida como a fase luteínica que dura entre 13 e 17 dias sendo caracterizada pelo desenvolvimento do corpo lúteo (CL), estrutura formada após a ruptura do folículo e liberação do óvulo. O CL produz a progesterona, hormônio responsável pela manutenção da gestação (Aisen, 2008). O período de receptividade sexual denominada de estro tem duração de 24 a 36 horas na ovelha (Jainudeen et al., 2004) e apresenta como característica a ocorrência da ovulação (Bicudo et al., 2005). A ovulação pode ser única ou múltipla sendo o predomínio de sua ocorrência no final do estro ou logo após o seu final (Gordon, 1997). A gestação corresponde ao período que transcorre da fecundação até a data do parto e tem duração de 144 a 156 dias. Essa variação pode está associada a fatores de ordem genética, fetal ou ambiental (Aisen, 2008).

A fisiologia reprodutiva das fêmeas envolve o efeito integrado dos hormônios sobre o ovário, útero e glândula mamária, possibilitando a fertilidade das matrizes para a produção de neonatos viáveis e consequentemente a lactação (Thompson, 2006). A hierarquia dos hormônios envolvidos na reprodução inicia-se com $\mathrm{o}$ hormônio liberador de gonadotrofina $(\mathrm{GnRH})$, secretado a partir de neurônios hipotalâmicos. Após a secreção o GnRH é liberado na circulação porta para a hipófise anterior, onde estimula a secreção de gonadotrofinas, hormônio folículo estimulante (FSH) e hormônio luteinizante (LH). Essas gonadotrofinas influenciam a função ovariana pela intensificação do desenvolvimento do folículo ovariano, ovulação e luteinização (Thompson, 2006).

O ovário da ovelha sexualmente madura tem peso variável de 0,5 a 3 gramas (Aisen, 2008), no qual os folículos ovarianos são suas unidades funcionais (Knight \& Glister, 2006) e no interior destes encontram-se os ovócitos (Fonseca, 2005). Os folículos asseguram a nutrição e o crescimento dos ovócitos (Gordon, 1997) e a secreção de hormônios como o estradiol, progesterona, inibina e ativina (Gordon, 1997, Aisen, 2008). O processo de ativação, crescimento e maturação folicular é iniciado durante o desenvolvimento fetal e ao nascerem, as cordeiras já tem estabelecido, em geral, o número de folículos primordiais em seus ovários (Moraes et al., 2002). O folículo primordial é constituído por um ovócito desprovido de zona pelúcida, circundado por uma única camada de células da granulosa e que ainda não sofreram nenhum crescimento (Thibault \& Levasseur, 2001). De acordo com Ginther et al. (2003) a população folicular é formada por folículos em diferentes estádios de crescimento. Os mesmos ressaltam que esses folículos são classificados em pré-antrais (primordiais, primários e secundários) e folículos antrais (folículos terciários). 
O desenvolvimento folicular em ovinos ocorre em um padrão de ondas. Durante o ciclo estral duas ou quatro ondas foliculares podem estar presentes e cada onda folicular é precedida por um aumento nos níveis circulantes do FSH (Ginther \& Kot, 1994, Deshpande et al., 1999, Evans, 2003). O início da onda folicular é caracterizado pelo recrutamento de um pequeno grupo de folículos (emergência folicular) que iniciam seu crescimento (Ginther et al., 2003). Destes apenas um ou mais folículos divergem em taxa de crescimento e atividade esteroidogênica (seleção folicular), tornando-se dominantes, ao passo que os restantes tornam-se subordinados (Evans, 2003). A inibina e o estradiol produzido pelo folículo dominante exercem uma retroalimentação negativa sobre a secreção de FSH o que acaba suprimindo o crescimento de um grupo adicional de folículos. A progesterona secretada pelo CL do folículo dominante durante o diestro impede à ocorrência de um pulso ovulatório de FSH e LH em reposta a secreção de estradiol pelo folículo dominante. Com o súbito declínio na concentração sérica de progesterona decorrente da luteóliseocorre a ovulação como resultado do efeito de retroalimentação positiva do estradiol sobre a secreção de LH (Thompson, 2006).

A atividade reprodutiva é realizada por eventos cíclicos e na ovelha o ciclo estral tem duração média de 14-19 dias. Ele é caracterizado pelo ritmo funcional dos órgãos reprodutivos, através das modificações cíclicas na morfofisiologia dos órgãos genitais e também dos hormônios relacionados (Aisen, 2008). Em zonas temperadas, a maioria das raças ovinas comportase como poliéstricas estacionais (Aisen, 2008). Nessas regiões o estímulo para a manifestação e/ou intensificação da atividade reprodutiva ocorre com decréscimo no número de horas de luz por dia - fotoperíodo negativo (Fonseca, 2005). A melatonina, hormônio produzido pela glândula pineal está envolvida no intermédio dessa resposta, atuando como um sinal de indicação da duração do dia ao eixo neuroendócrino (Jainudeen et al., 2004). Em latitudes próximas a linha do Equador, a atividade reprodutiva apresenta - se mais prolongada ao longo do ano (Aisen, 2008) e entre os principias fatores que a influenciam estão à sazonalidade na oferta de alimento (Fonseca, 2005) e as condições sanitárias do rebanho e do local de criação (Aisen, 2008).

\section{Origem e caracterização das raças Morada Nova e Somalis Brasileira}

Os ovinos, possivelmente, fizeram parte dos primeiros animais domésticos introduzidos no Brasil durante o período colonial. Inicialmente vieram grupos genéticos portugueses e espanhóis, bem como aqueles trazidos da África juntamente com o tráfico de escravos (Fernandes Júnior, 2010). Este material genético foi submetido à seleção natural em diferentes ambientes, nos quais desenvolveram características específicas de adaptação às condições locais (Egito et al., 2002). As raças naturalizadas de ovinos brasileiros são constituídas em geral por animais de pequeno porte, que apresentam alta resistência a doenças e parasitas (Paiva et al., 2005). Dentre as principais raças nativas de ovinos deslanados do Nordeste do Brasil, destacam- se a Morada Nova e a Somalis Brasileira. Os primeiros animais da raça Morada Nova (Figura 1) foram identificados pelo professor e zootecnista Otávio Domingues, no município de Morada Nova no estado do Ceará, em 1937. Posteriormente foi constatada em 1941 a existência de mais exemplares dessa raça em outras cidades do interior cearense e do estado do Piauí (Facó et al., 2008).

Villela et al. (2005), ressaltaram que tanto carneiros ibéricos, quanto africanos, tenham contribuído para a formação desta raça, tendo os descendentes destes, certamente, passado por processos de seleção natural. Os mesmos relataram que os ovinos da raça Morada Nova têm como padrão racial o pequeno porte, ausência de lã e de chifre, queixo curto, olhos pequenos e cascos pretos.

Atualmente é reconhecida pela Associação Brasileira de Criadores de Ovinos, duas variedades dessa raça, a vermelha, variando de intensidade vermelha escura a clara e a branca. Na idade adulta, os machos chegam a pesar de 40 a $60 \mathrm{~kg}$ e as fêmeas de 30 a $50 \mathrm{~kg}$ de peso vivo (Facó et al., 2008). Os animais dessa raça são muito prolíficos, possui alta taxa de fertilidade, boa habilidade materna, precocidade reprodutiva, longa duração da estação reprodutiva e elevada adaptabilidade, características que a tornam raça materna por excelência (Villela et al., 2005; Facó et al., 2008).O pequeno porte, rusticidade e adaptabilidade dos ovinos Morada Nova às condições climáticas da região semiárida, os tornam importantes nas pequenas propriedades, onde desempenham uma grande função social e 
econômica, fornecendo proteína de alta qualidade além de propiciar uma renda adicional as populações rurais (Silva Sobrinho et al., 2005). Gonzaga Neto et al. (2006) ressaltaram que nas condições de Nordeste brasileiro, os ovinos da raça Morada Nova mostraram-se mais precoces em comparação com as raças Santa Inês e Somalis Brasileira, pois esta raça é portadora de fatores genéticos que possibilitam um melhor desenvolvimento fisiológico e sexual tornando-a bem adaptada, e assim, mesmo em condições adversas, atinge precocemente a puberdade.
Facó et al. (2008) destacaram que apesar do crescimento que vem sendo observado no efetivo ovino brasileiro nas últimas décadas, os rebanhos da raça Morada Nova vem reduzindo de tamanho a cada ano. Os mesmos enfatizaram que muitos criadores têm optado pela criação de genótipos mais produtivos, como o Santa Inês. Também citaram que somado a isso, existe ainda a ocorrência de cruzamentos indiscriminados com ovinos de raças exóticas, que vêm pondo em risco a preservação da raça, que apresenta características relevantes em sistemas de produção de carne ovina, não observadas em outras raças nativas.

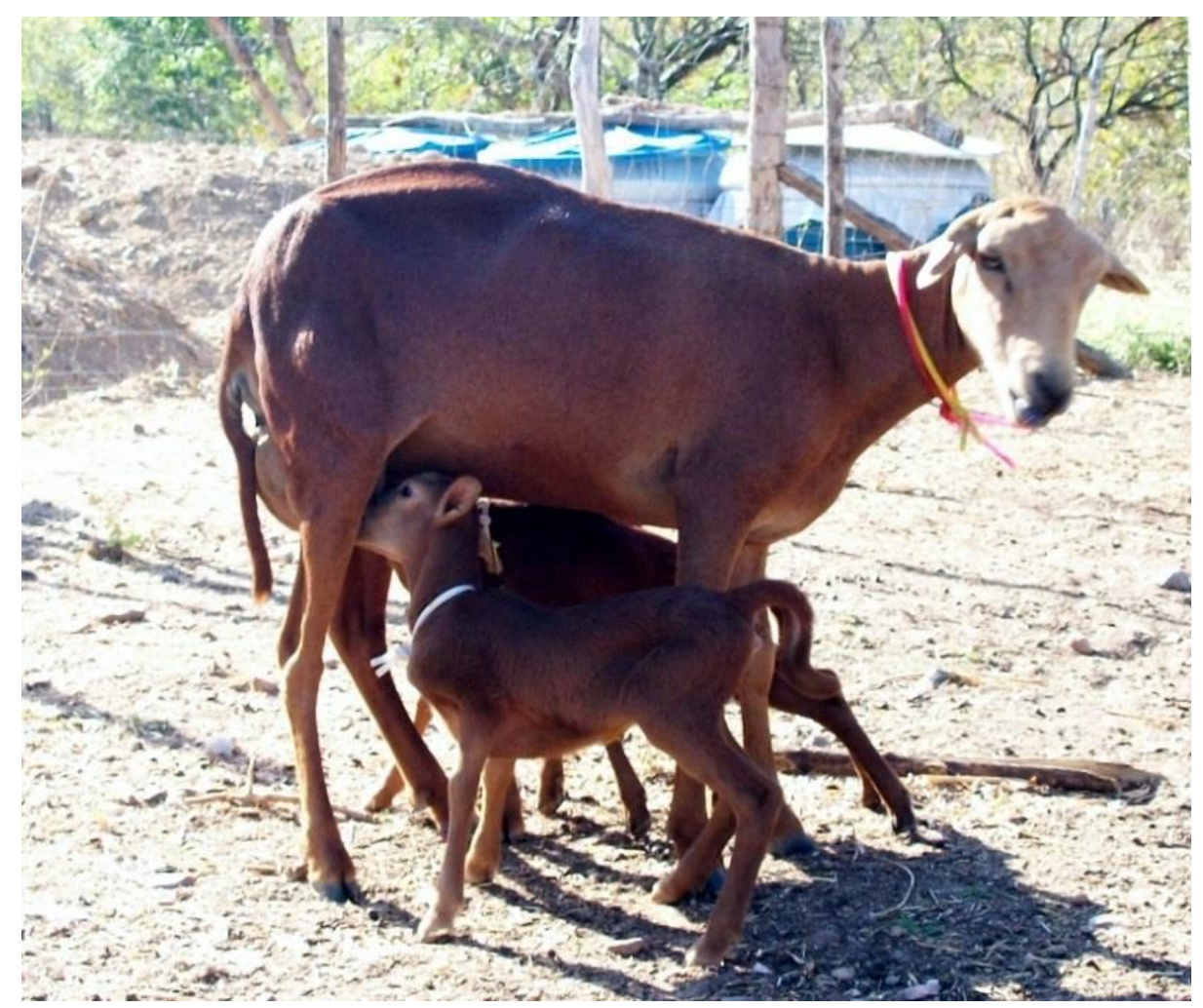

Figura 1. Ovinos Morada Nova- Foto: Rafael Teixeira de Sousa

A respeito da raça Somalis Brasileira (Figura 2), segundo a Associação Brasileira de Criadores de Ovinos (ARCO), os ovinos dessa raça pertencem ao grupo de ovinos de "garupa gorda", originário do "corno da África", região formada pela Somália e Etiópia. No continente Americano, a raça Somalis Brasileira foi primeiramente introduzida nas ilhas de Tobago e Granada, e nos territórios da Colômbia e Brasil, e, mais recentemente, na Guiana e Venezuela (Silva et al., 1998).

Magalhães et al. (2010) relataram que os atuais animais originaram - se após seleção e adaptação local daqueles da raça Black Head Persian, introduzida no Brasil, no ano de 1939 por criadores do estado do Rio de Janeiro. Porém, esses animais não se adaptaram ao clima e foram trazidos para a região Nordeste, onde foram disseminados particularmente nos estados do Ceará e Rio Grande do Norte. A raça Somalis Brasileira já se afastou bastante do tronco original, sendo mais prolífica, de garupa menos gorda e com alguma lã pelo corpo o que sugere ter ocorrido infusão de raças que apresentavam essas características (Correia Neto et al., 2006).

Segundo Magalhães et al. (2010), os ovinos da raça Somalis Brasileira são bem rústicos e muito bem adaptados às condições edafoclimáticas da região Nordeste. São animais 
de porte médio, deslanados e mochos. $\mathrm{O}$ padrão racial desses animais é caracterizado pela pelagem branca, com a cabeça e o pescoço preto, sendo permissível a tonalidade parda (vermelha) nestas partes. Na idade adulta os machos chegam a pesar de 40 a $60 \mathrm{~kg}$ e as fêmeas entre 30 e 50 $\mathrm{kg}$.

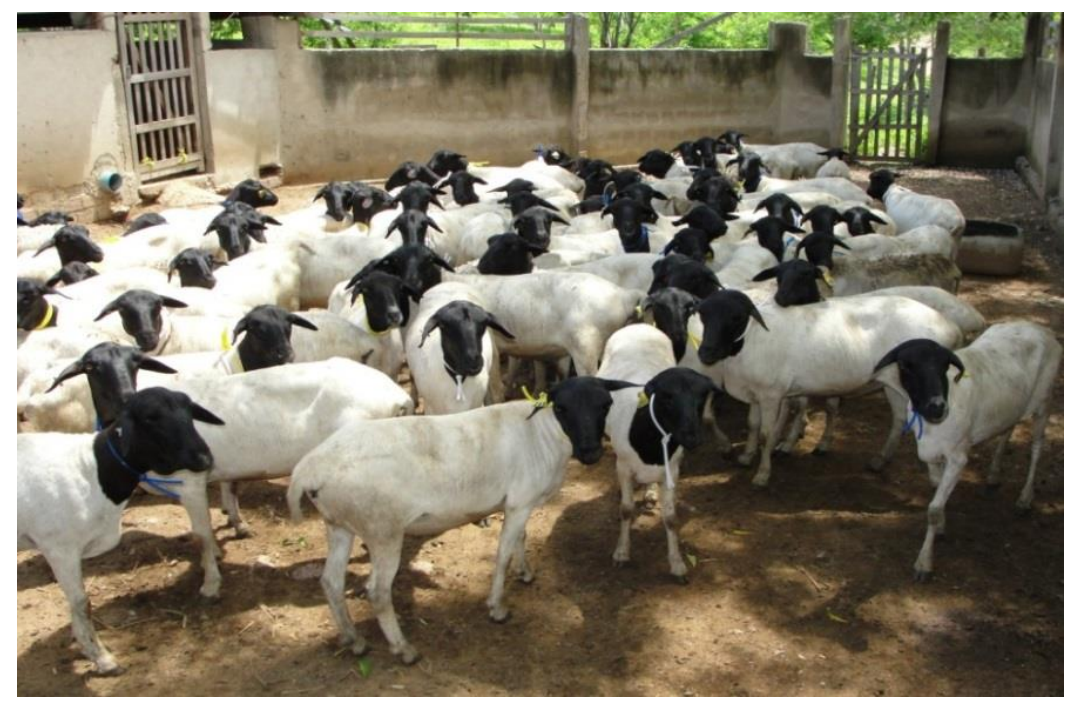

Figura 2. Ovelhas Somalis Brasileira- Foto: Rafael Teixeira de Sousa

As ovelhas desta raça, apesar de apresentarem crescimento mais lento, quando comparada a raças especializadas, adaptam-se bem as condições climáticas do Nordeste do Brasil. O porte pequeno pode favorecer sua eficiência de produção, já que, matrizes com menor peso adulto apresentam menor exigência nutricional para sua mantença quando comparadas com ovelhas de maior porte (Magalhães et al., 2010). A Somalis Brasileira acumula reserva de gordura na garupa durante a época de alimentação abundante, como estratégia energética a ser utilizada durante a época de escassez de alimentos. Assim, Silva et al. (1998) afirmaram que a raça pode ser criada nas regiões em que as condições alimentares são menos favoráveis e não dispõem de áreas potenciais para produção de forragem e irrigação para produção de grãos.

Silva et al. (1998) reportaram em 307,2 dias a idade à puberdade de ovinos Somalis Brasileira, com $18,3 \mathrm{~kg}$ de peso vivo. Seu porte pequeno favorece sua eficiência de produção, por reduzir custo de manutenção, além de ser considerada como uma raça materna. A baixa prolificidade da raça Somalis é considerada favorável para uma alta viabilidade e melhor desenvolvimento corporal das crias e reduzido estresse das ovelhas em lactação (Magalhães et al., 2010). Segundo Silva et al. (1998), ovinos da raça Somalis Brasileira são indicados para cruzamento com ovelhas Sem Padrão Racial Definido, com o intuito de produzir mestiços com melhor conformação de carcaça, na região semiárida do Nordeste brasileiro. Atualmente, os rebanhos desta raça encontram-se distribuídos em estados da região Nordeste, em núcleos fechados, pertencentes a instituições de pesquisa ou a criadores de elite, e disponibilizados para a venda em feiras e em exposições agropecuárias (Silva \& Lôbo, 2006). Gonzaga Neto et al. (2006) reportaram uma alta taxa de fertilidade em ovelhas Morada Nova e Somalis Brasileira e a influência do grupo genético para a taxa de prolificidade $(\mathrm{P}<0,05)$ (Tabela 1$)$.

Esses resultados evidenciam o grande potencial reprodutivo desses grupos genéticos. Contudo é importante ressaltar que a eficiência reprodutiva do rebanho depende de vários outros fatores, dentre os quais das estratégias de manejo nutricional que garantam a expressão desse potencial. Estes mesmos autores verificaram que existe uma alta associação entre o escore de condição corporal (ECC) ao parto com a prolifidade (Tabela 2).

Como pode se observar o genótipo das unidades experimentais influenciou $(\mathrm{P}<0,05)$ à condição corporal ao parto, evidenciando que o escore das matrizes comportou-se de maneira inversamente proporcional à taxa de prolificidade, ou seja, quando maior a prolificidade, menor o ECC. 
Tabela1. Fertilidade e prolificidade de ovelhas Somalis Brasileira e Morada Nova

Grupo Genético

Fertilidade (\%)

Prolificidade

Somalis Brasileira $(\mathrm{n}=67)$

$\begin{array}{ll}90,67^{\mathrm{a}} & 1,04^{\mathrm{b}} \\ 92,00^{\mathrm{a}} & 1,51^{\mathrm{a}}\end{array}$

Morada Nova $(\mathrm{n}=69)$

$92,00^{\circ}$

$1,51^{\mathrm{a}}$

Adaptado de Gonçalves et al., 2012. Médias, na coluna, seguidas de diferentes letras diferiram $(\mathrm{P}<0,05)$ pelo teste Exato de Fisher. Fertilidade = número de ovelhas paridas / número de ovelhas expostas à monta $\mathrm{x} 100$; Prolificidade $=$ número de cordeiros nascidos $/$ número de ovelhas paridas

Esta diferença na escala de condição corporal pós-parto é associada ao fato de que ovelhas que gestam mais de um feto apresentam maior exigência nutricional quando comparadas as ovelhas de parto simples, exigindo um manejo nutricional no terço final de gestação para evitar redução no escore de condição corporal em função do maior percentual de partos gemelares.

Tabela 2. Peso e escore de condição corporal (ECC) ao parto de ovelhas Morada Nova e Somalis Braasileira

\begin{tabular}{lcc}
\hline Grupo genético & Peso ao parto & ECC ao parto \\
\hline Somalis Brasileira $(\mathrm{n}=67)$ & $27,041^{\mathrm{a}}$ & $2,52^{\mathrm{a}}$ \\
Morada Nova $(\mathrm{n}=68)$ & $27,517^{\mathrm{a}}$ & $2,04^{\mathrm{b}}$
\end{tabular}

Adaptado de Gonçalves et al., 2012. Médias, na coluna, seguidas de diferentes letras mostram diferenças $(\mathrm{P}<0,05)$ pelo teste $\mathrm{t}$ de Student. (ECC- escore de condição corporal)

O menor escore de condição corporal ao parto das ovelhas Morada Nova pode estar relacionado à maior prolificidade dessas matrizes (Tabela 1) associado às maiores exigências nutricionais nas ovelhas de gestação gemelar durante o terço final de gestação. De acordo com o NRC (2007), a exigência de energia líquida de ovelhas com 1, 2 e 3 fetos aos 140 dias de gestação é de 260, 440 e $570 \mathrm{Kcal} / \mathrm{dia}$, respectivamente.

\section{Considerações finais}

Assim, tanto os ovinos da raça Morada Nova quanto da raça Somalis Brasileira apresentam um elevado potencial reprodutivo, uma vez que as fêmeas destes grupos genéticos são poliéstricas anuais, apresentando estro, ovulação e parição durante todo o ano. Nesse sentido,o emprego de estratégias de manejo reprodutivo, nutricional e sanitário associados ao melhoramento genético pode contribuir ainda mais para a expressão desse potencial, uma vez que as condições do ambiente criatório são de grande importância para o aumento dos índices zootécnicos dos animais pertencentes a esses genótipos.

\section{Referências bibliográficas}

Aisen, E. 2008. Reprodução ovina e caprina. MedVet.
Bicudo, S., Azevedo, H., Silva Maia, M., Sousa, D. \& Rodello, L. 2005. Aspectos peculiares da inseminação artificial em ovinos. Acta Science Veteterinária, 33, 127-130.

Bomfim, M., Albuquerque, F. \& Souza, R. 2014. Papel da nutrição sobre a reprodução ovina. Acta Veterinaria Brasilica, 8, 372-379.

Chemineau, P. \& Delgadillo, J. 1993. Neuroendocrinología de la reproducción en el caprino. Revista Científica, 3, 113-121.

Correia Neto, J., Costa, A. \& Reis, J. 2006. Parâmetros reprodutivos de ovelhas Santa Inês e suas cruzas com machos das raças Dorper e Somalis Brasileira, obtidas por inseminação artificial laparoscópica com sêmen congelado. Ciência Veterinária Tropical, 9, 63-73.

Deshpande, D., Ravindra, J., Narendranath, R. \& Narayana, K. 1999. Ovarian antral follicular dynamics and serum progesterone concentration during the oestrous cycle of Bannur ewes. The Indian Journal of Animal Sciences, 69, 932-934.

Egito, A., Mariante, A. \& Albuquerque, M. 2002. Programa brasileiro de conservação de recursos genéticos animais. Archivos de Zootecnia, 51, 39-52. 
Evans, A. 2003. Ovarian follicle growth and consequences for fertility in sheep. Animal Reproduction Science, 78, 289-306.

Facó, O., Paiva, S., Alves, L., Lôbo, R. \& Villela, L. 2008. Morada Nova: Origem, Características e Perspectivas. Documento, $75,43$.

Fernandes Júnior, G. 2010. Desempenho produtivo e qualidade da carne de ovinos terminados em pastagem irrigada no semiárido nordestino. 2010. 88f. Animal Science. Universidade Federal do Ceará, Fortaleza.

Fonseca, J. 2005. Estratégias para o controle do ciclo estral e superovulação em ovinos e caprinos. Revista Brasileira de Reprodução Animal, 16, 1-9.

Ginther, O., Beg, M., Donadeu, F. \& Bergfelt, D. 2003. Mechanism of follicle deviation in monovular farm species. Animal reproduction science, 78, 239-257.

Ginther, O. \& Kot, K. 1994. Follicular dynamics during the ovulatory season in goats. Theriogenology, 42, 987-1001.

Gonzaga Neto, S., Silva Sobrinho, A. G., Lopes, N. M. B., Zeola, C. A. T. M., Azevedo Silva, A. M., Morais, J. \& Pereira Filho, Â. C. D. F. 2006. Características quantitativas da carcaça de cordeiros deslanados Morada Nova em função da relação volumoso: concentrado na dieta1. Revista Brasileira de Zootecnia, 35, 1487-1495.

Gordon, I. 1997. Controlled reproduction in sheep and goats. $\mathrm{Cab}$ International, Cambridge, UK: University Press.

Jainudeen, M., Wahid, H. \& Hafez, E. 2004. Ovinos e caprinos. In: Hafez, E. S. E. \& Hafez, B. (eds.) Reprodução Animal. Manole, São Paulo.

Knight, P. G. \& Glister, C. 2006. TGF- $\beta$ superfamily members and ovarian follicle development. Reproduction, 132, 191-206.

Magalhães, A. F. B., Facó, O., Lôbo, R. N. B. \& Villela, L. C. V. 2010. Raça Somalis Brasileira: Origem, Características Reprodutivas e Desenvolvimento Ponderal. Documento, 99, 29.

Moraes, J., Souza, C., Gonçalves, P., Fritas, V. \& Lopes Júnior, E. 2002. Controle do estro e da ovulação em bovinos e ovinos. In: Gonçalves,
P. B. D., Figueiredo, J. R. \& Freitas, V. J. F. (eds.) Biotécnicas aplicadas à reprodução animal. São Paulo: Varela Editora e Livraria Ltda.

NRC. 2007. Nutrient requirements of small ruminants: sheep, goats, cervids, and new world camelids, 7th rev. edn. Natl. Acad. Press, Washington, DC., Washington.

Paiva, S. R., Silvério, V. C., Egito, A. A., McManus, C., Faria, D. A., Mariante, A. d. S., Castro, S. R., Albuquerque, M. d. S. M. \& Dergam, J. A. 2005. Genetic variability of the Brazilian hair sheep breeds. Pesquisa Agropecuária Brasileira, 40, 887-893.

Silva, F. L. R., Araújo, A. M. \& Figueiredo, É. A. P. 1998. Características de crescimento e de reprodução em ovinos Somalis no Nordeste Brasileiro. Revista Brasileira de Zootecnia, 27, 1107-1114.

Silva Sobrinho, A. G., Purchas, R. W., Kadim, I. T. \& Yamamoto, S. M. 2005. Características de qualidade da carne de ovinos de diferentes genótipos e idades ao abate. Revista Brasileira de Zootecnia, 34, 1070-1078.

Sousa, R. 2012. Flushing de ácidos graxos sobre a eficiência reprodutiva em ovinos. Animal Science. Universidade Estadual Vale do Acaraú, Sobral.

Thibault, C. \& Levasseur, M.-C. 2001. La reproduction chez les mammifères et l'homme. Editions Quae.

Thompson, F. 2006. Reprodução em mamíferos do sexo feminino. In: Reece, W. \& Dukes (eds.) Fisiologia dos Animais Domésticos. Guanabara Koogan, Rio de Janeiro.

Viana, J. G. A. 2008. Panorama geral da ovinocultura no mundo e no Brasil. Revista Ovinos, 4, 1-9.

Recebido em Julho 23, 2015

Aceito em Setembro 17, 2015

License information: This is an open-access article distributed under the terms of the Creative Commons Attribution License, which permits unrestricted use, distribution, and reproduction in any medium, provided the original work is properly cited. 